\title{
Strategy for obtaining solid fusion at L5-S1 in adult spinal deformity: risk factor analysis for nonunion at L5-S1
}

\author{
Ki Young Lee, MD, Jung-Hee Lee, MD, Kyung-Chung Kang, MD, Sung Joon Shin, MD, \\ Won Ju Shin, MD, Sang-Kyu Im, MD, and Joon Hong Park, MD \\ Department of Orthopedic Surgery, Graduate School, College of Medicine, Kyung Hee University, Seoul, Korea
}

\begin{abstract}
OBJECTIVE Maintaining lumbosacral (LS) arthrodesis and global sagittal balance after long fusion to the sacrum remains an important issue in the surgical treatment for adult spinal deformity (ASD). The importance and usefulness of LS fixation have been documented, but the optimal surgical long fusion to the sacrum remains a matter for debate. Therefore, the authors performed a retrospective study to evaluate fusion on CT scans and the risk factors for LS pseudarthrosis (nonunion) after long fusion to the sacrum in ASD.
\end{abstract}

METHODS The authors performed a retrospective study of 59 patients with lumbar degenerative kyphosis (mean age 69.6 years) who underwent surgical correction, including an interbody fusion of the L5-S1, with a minimum 2-year follow-up. Achievement of LS fusion was evaluated by analyzing 3D-CT scans at 3 months, 6 months, 9 months, 1 year, and 2 years after surgery. Patients were classified into a union group $(n=36)$ and nonunion group $(n=23)$. Risk factors for nonunion were analyzed, including patient and surgical factors.

RESULTS The overall fusion rate was $61 \%$ (36/59). Regarding radiological factors, optimal sagittal balance at the final follow-up significantly differed between two groups. There were no significant differences in terms of patient factors, and no significant differences with respect to the use of pedicle subtraction osteotomy, the number of fused segments, the proportion of anterior versus posterior interbody fusion, S2 alar iliac fixation versus conventional iliac fixation, or loosening of sacral or iliac screws. However, the proportion of metal cages to polyetheretherketone cages and the proportion of sacropelvic fixation were significantly higher in the union group $(p=0.022$ and $p<0.05$, respectively).

CONCLUSIONS LS junction fusion is crucial for global sagittal balance, and the use of iliac screws in addition to LS interbody fusion using a metal cage improves the outcomes of long fusion surgery for ASD patients.

https://thejns.org/doi/abs/10.3171/2020.2.SPINE191181

KEYWORDS adult spinal deformity; lumbar degenerative kyphosis; lumbosacral fusion; sacropelvic fixation; interbody fusion

$\mathrm{T}$ HE prevalence of adult spinal deformity (ASD) has been rising recently to more than $60 \%$ among patients aged 60 years and older. ${ }^{1}$ ASD is a disease that induces an imbalance in the normal spinal function, which negatively affects patients' quality of life. The goal of ASD surgery is to restore sagittal balance and achieve solid arthrodesis, ${ }^{2}$ and surgical treatment requires solid distal fixation to the sacrum, along with long fusion. ${ }^{3-6}$

Maintaining lumbosacral (LS) arthrodesis and global sagittal balance after long fusion to the sacrum remains an important issue in surgical treatment of ASD; the impor- tance and usefulness of LS fixation, serving as the anchor in long constructs, have been documented in several biomechanical studies. ${ }^{7}$

Poor bone quality of the sacrum, complexity of the sacral anatomy, and high biomechanical forces inflicted on the LS junction induce pseudarthrosis (nonunion) of the LS junction. ${ }^{8,9}$ Inappropriately restored sagittal alignment also increases the risk of LS pseudarthrosis by elevating biomechanical stress on the LS junction. ${ }^{10}$

For these reasons, complete sacropelvic fixation using bilateral iliac and bicortical pedicle screws, supplementary

ABBREVIATIONS ALIF = anterior lumbar interbody fusion; $A S D=$ adult spinal deformity; $B M D=$ bone mineral density; $B M I=$ body mass index; $L D K=$ lumbar degenerative kyphosis; LL = lumbar lordosis; LS = lumbosacral; ODI = Oswestry Disability Index; PEEK = polyetheretherketone; PI = pelvic incidence; PLIF = posterior lumbar interbody fusion; PSO = pedicle subtraction osteotomy; PT = pelvic tilt; rhBMP-2 = recombinant human bone morphogenetic protein-2; SS = sacral slope; SVA = sagittal vertical axis; S2AI = S2 alar iliac; VAS = visual analog scale.

SUBMITTED October 1, 2019. ACCEPTED February 10, 2020.

INCLUDE WHEN CITING Published online April 17, 2020; DOI: 10.3171/2020.2.SPINE191181. 
points of sacral fixation, and anterior column support at L5-S1 were introduced to reduce LS pseudarthrosis, ${ }^{3,9}$ and the use of osteobiological materials such as demineralized bone matrix and recombinant human bone morphogenetic protein-2 (rhBMP-2) has increased fusion rates. ${ }^{5,11,12}$

Despite the fact that the LS fusion rate is improving because of advances in instrumentation techniques and circumferential LS fusion, the optimal surgical long fusion to the sacrum remains a matter of debate. Furthermore, reported LS pseudarthrosis has diverse etiologies, with no consensus regarding the surgical technique and fusion grade. Therefore, we performed a retrospective study to evaluate fusion on CT and the risk factors for LS pseudarthrosis (nonunion) in a single etiology of lumbar degenerative kyphosis (LDK) with consistent surgical instruments and corrective methods.

\section{Methods}

This study was approved by our institutional review board. Informed consent was waived as our study was performed retrospectively.

\section{Patient Selection}

This study was a retrospective review of consecutive patients $\geq 60$ years of age with ASD enrolled from 2006 to 2015 .

The inclusion criteria were as follows: 1) patients 60 years or older who had ASD accompanied by sagittal malalignment (sagittal vertical axis [SVA] $>50 \mathrm{~mm}$, pelvic incidence $[\mathrm{PI}]$ - lumbar lordosis [LL] $>10^{\circ}$, and pelvic tilt $[\mathrm{PT}]>25^{\circ}$ ) with a minimum of 2 years of follow-up after deformity correction; 2) patients who underwent longsegment fusion ${ }^{3}$ to $\mathrm{S} 1$ as a surgical treatment by a single surgeon at a single institution; and 3) a single etiology of LDK; patients who clearly showed atrophy of back musculature on the cross-sectional area (axis slice) on MRI and CT scanning as a diagnostic criterion for LDK and clinical signs including walking difficulty with stooping, inability to lift heavy objects in the front, difficulty in climbing slopes, and the need for elbow support when working in the kitchen, resulting in a hard callus on extensor surfaces of the elbow. ${ }^{13-15}$

Patients satisfying the inclusion criteria were classified into those with union and those with nonunion depending on the achievement of radiological fusion seen on 3D-CT scans.

\section{Radiological Measurement}

Sagittal alignment was evaluated using lateral $14 \times$ 36 -inch full-spine radiographs obtained with the patients standing in a neutral, unsupported position with arms in the clavicle position. ${ }^{16}$ All the digital radiographs from the preoperative, postoperative, and latest follow-up periods were evaluated using a picture archiving and communication system that was developed to accurately calculate parameters by magnifying anatomical landmarks of the spine and pelvis on lateral views. ${ }^{17}$ All radiological parameters were measured by 3 professional orthopedic surgeons, and the mean measurements were used for analysis.

We evaluated SVA, thoracic kyphosis, thoracolumbar junctional angle, LL, LS junctional angle, PI, PT, and sacral slope (SS). Optimal and suboptimal sagittal balances were defined as SVA $\leq 50 \mathrm{~mm}$ and $>50 \mathrm{~mm}$, respectively. ${ }^{18}$ PI, PT, and SS were measured on standing lateral radiographs of the pelvis using methods described in previous reports. ${ }^{17,19}$

Achievement of LS fusion was evaluated using a 4-point scale suggested by Whang et al. ${ }^{20}$ by analyzing 3D-CT scans at 3 months, 6 months, 9 months, 1 year, and 2 years after surgery (Fig. 1). Grade 1 was defined as no evidence of fusion, and grade 2 was defined as ossification within the disc space but no bridging with the endplate. Grade 3 was defined as less than $50 \%$ of bridging with the endplate, and grade 4 was defined as more than $50 \%$ of bridging with the endplate. Grades 3 and 4 were considered to represent fusion.

\section{Risk Factor Analysis}

We evaluated the risk factors for LS pseudarthrosis, including patient factors (age, bone mineral density [BMD], body mass index [BMI], and history of previous spine surgery) and surgical factors (anterior lumbar interbody fusion $[\mathrm{ALIF}]$ vs posterior lumbar interbody fusion [PLIF], cage design and material [metal \{titanium\} vs polyetheretherketone $\{\mathrm{PEEK}\}]$, use of pedicle subtraction osteotomy [PSO] and sacropelvic fixation, number of fused segments, S2 alar iliac [S2AI] fixation vs conventional iliac fixation, and loosening of sacral or iliac screw).

\section{Clinical Outcome Assessment}

The clinical assessment was performed using the Oswestry Disability Index (ODI) and visual analog scale (VAS) for rating back and radiating pain. The preoperative, 3-month postoperative, and last follow-up values of the two groups were compared. Additionally, intraoperative and postoperative complications (motor deficit) were also examined.

\section{Statistical Analysis}

For continuous variables, ANOVA with a Student ttest was used for variables with normality, and the MannWhitney test was used for variables without normality. Categorical variables were assessed using the chi-square test and compensated using Fisher's exact test to evaluate every considerable risk factor (SAS 9.3, SAS Institute Inc.). Moreover, the multivariate logistic regression model (backward elimination method) was applied using the predictive factors of L5-S1 fusion to determine the risk factors of L5-S1 nonunion. A p value of $<0.05$ was considered statistically significant.

\section{Results}

\section{Baseline Characteristics}

Table 1 presents the baseline characteristics. At the time of the study, the database included 119 patients, and after applying the inclusion criteria, 59 patients were identified for analysis. The mean age at surgery was $69.6 \pm 5.9$ years. The mean length of the follow-up period was $87.4 \pm 37.5$ months. The upper instrumented vertebra was at T10 in 

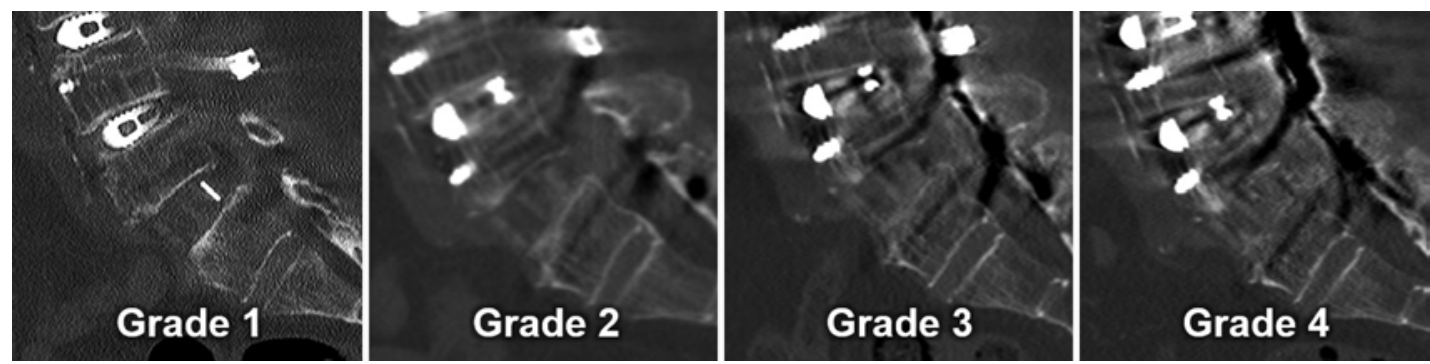

FIG. 1. Three-dimensional CT scan grading scale for determining fusion status. Grade 1 is defined as no fusion evidence, and grade 2 is defined as ossification within the disc space but no bridging with the endplate. Grade 3 is defined as less than $50 \%$ of bridging with the endplate, and grade 4 is defined as more than $50 \%$ of bridging with the endplate.

45 patients, at $\mathrm{T} 12$ in 7 patients, and $\mathrm{L} 1$ in 7 patients. Regarding the surgical technique used for interbody fusion at L5-S1, ALIF was used for 44 patients, and PLIF was used for 15 patients. Sacropelvic fixation was performed in 30 patients, and PSO was performed in 48 patients.

\section{Comparison of Radiographic Parameters Between Union and Nonunion Groups}

Table 2 lists the radiographic parameters of the union and nonunion groups. The two groups did not significantly differ in their radiographic parameters before surgery, after surgery, and at the final follow-up ( $p>0.05)$. The mean SVA was $156.4 \pm 65.7 \mathrm{~mm}$ before surgery, $-5 \pm 29.5 \mathrm{~mm}$ after surgery, and $24.2 \pm 42.3 \mathrm{~mm}$ at final follow-up. The mean LL was $1.7^{\circ} \pm 19.6^{\circ}$ before surgery, $-66.1^{\circ} \pm 13^{\circ}$ after surgery, and $-62.4^{\circ} \pm 14.7^{\circ}$ at the final follow-up. The mean PI-LL did not significantly differ between the groups, at $-9.6^{\circ} \pm 13.1^{\circ}(\mathrm{p}>0.05)$.

Both groups showed optimal sagittal balance after surgery; however, they significantly differed at the final follow-up, with a rate of $88.9 \%$ for the union group and $60.9 \%$ for the nonunion group $(\mathrm{p}=0.022)$.

\section{Predictive Risk Factors for LS Pseudarthrosis}

Table 3 presents the predictive risk factors for LS pseudarthrosis in the union and nonunion groups. The overall fusion rate was $61 \%(36 / 59)$. The number of patients who showed LS fusion was 10 at 3 months (28\%), 9 at 6 months (25\%), 5 at 9 months (14\%), 4 at 1 year (11\%), and 8 at 2 years (22\%) postoperatively.

There were no significant differences in terms of patient factors, including age, BMI, BMD, BMD T-score, and history of spine surgery between the union and nonunion groups $(\mathrm{p}>0.05)$. However, regarding surgical factors, the proportion of metal cages to PEEK cages and the proportion of sacropelvic fixation were significantly higher in the union group $(\mathrm{p}=0.022$ and $<0.05$, respectively). There were no significant differences between the union and nonunion groups with respect to the use of PSO, the number of fused segments, the proportion of ALIF to PLIF procedures, S2AI fixation versus conventional iliac fixation, or loosening of sacral or iliac screws $(\mathrm{p}>0.05)$. Moreover, we further studied the risk factors among the predicative factors (Table 3) of L5-S1 nonunion, and as shown by backward stepwise logistic regression (the backward elimination method; Table 4), sacropelvic fixation $(\beta-2.218$; OR 0.109; 95\% CI 0.028-0.427; $\mathrm{p}<0.05)$ and PEEK cage use ( $\beta$ 1.482; OR 4.402; 95\% CI 0.966-20.054; $\mathrm{p}<0.05$ ) were crucial risk factors for the occurrence of L5-S1 nonunion.

\section{Comparison of Clinical Outcomes Between the Union and Nonunion Groups}

Clinical results were evaluated using the results obtained preoperatively, postoperatively, and at the last follow-up (Table 2). VAS scores of back and radiating pain and ODI scores improved postoperatively and at the last follow-up compared to those preoperatively, but the union group showed statistically lower ODI scores at the last follow-up visit and lower VAS scores for low-back pain

TABLE 1. Demographic and baseline data

\begin{tabular}{lc}
\hline Characteristic & Value \\
\hline No. of patients & 59 \\
\hline Sex & 57 \\
\hline Female & 2 \\
\hline Male & $69.6 \pm 5.9$ \\
\hline Age at surgery (yrs) & $87.4 \pm 37.5$ \\
\hline Follow-up (mos) & $25.6 \pm 3.5$ \\
\hline BMI (kg/m $\left.{ }^{2}\right)$ & $0.97 \pm 0.24$ \\
\hline BMD (g/cm $)$ & $-1.3 \pm 1.57$ \\
\hline BMD T-score $\left(\mathrm{g} / \mathrm{cm}^{2}\right)$ & $7.4 \pm 1.3$ \\
\hline Fused segments & \\
\hline UIV & 45 \\
\hline T10 & 7 \\
\hline T12 & \\
\hline L1 & 59 \\
\hline LIV & 44 \\
\hline Sacrum & 15 \\
\hline L5-S1 fusion & 30 \\
\hline ALIF & 48 \\
\hline PLIF & \\
\hline Sacropelvic fixation & \\
\hline PSO & \\
\hline
\end{tabular}

LIV = lowermost instrumented vertebra; UIV = uppermost instrumented vertebra.

Data are presented as the mean \pm SD or as the number of patients. 
TABLE 2. Radiological and clinical parameters between union and nonunion groups

\begin{tabular}{|c|c|c|c|}
\hline Parameter & Union $(n=36)$ & Nonunion $(n=23)$ & $p$ Value \\
\hline \multicolumn{4}{|l|}{ SVA (mm) } \\
\hline Preoperative & $166.1 \pm 64$ & $141.3 \pm 67$ & 0.160 \\
\hline IMPO & $-11.2 \pm 26.6$ & $4.64 \pm 31.7$ & 0.142 \\
\hline Last follow-up & $21 \pm 46.3$ & $29.2 \pm 35.6$ & 0.550 \\
\hline \multicolumn{4}{|c|}{ IMPO sagittal alignment (no. of patients) } \\
\hline Optimal & $36(100 \%)$ & $20(87 \%)$ & \multirow{2}{*}{$0.054 \dagger$} \\
\hline Suboptimal & 0 & $3(13 \%)$ & \\
\hline \multicolumn{4}{|c|}{ Last sagittal alignment (no. of patients) } \\
\hline Optimal & $32(88.9 \%)$ & $14(60.9 \%)$ & \multirow{2}{*}{$0.022^{*} \ddagger$} \\
\hline Suboptimal & $4(11.1 \%)$ & $9(39.1 \%)$ & \\
\hline \multicolumn{4}{|l|}{ Thoracic kyphosis $\left({ }^{\circ}\right)$} \\
\hline Preoperative & $1.8 \pm 13.6$ & $8.5 \pm 15.1$ & 0.080 \\
\hline IMPO & $22.3 \pm 13.7$ & $21 \pm 12.8$ & 0.727 \\
\hline Last follow-up & $27.2 \pm 27.7$ & $27.7 \pm 14.2$ & 0.893 \\
\hline \multicolumn{4}{|l|}{ Thoracolumbar junction $\left({ }^{\circ}\right)$} \\
\hline Preoperative & $-0.5 \pm 15.2$ & $7.4 \pm 17.8$ & 0.073 \\
\hline IMPO & $-19 \pm 19.9$ & $-12.9 \pm 17.2$ & 0.127 \\
\hline Last follow-up & $-16.3 \pm 20.1$ & $-10.2 \pm 18.4$ & 0.107 \\
\hline \multicolumn{4}{|l|}{ Lumbar lordosis $\left({ }^{\circ}\right)$} \\
\hline Preoperative & $5.5 \pm 18$ & $-4.4 \pm 20.9$ & 0.235 \\
\hline IMPO & $-66.7 \pm 14.5$ & $-65.1 \pm 10.6$ & 0.659 \\
\hline Last follow-up & $-64 \pm 15.9$ & $-60 \pm 12.4$ & 0.169 \\
\hline PI-LL & $-12.3 \pm 12.1$ & $-5.6 \pm 13.9$ & 0.055 \\
\hline \multicolumn{4}{|l|}{ Lumbosacral junction $\left(^{\circ}\right)$} \\
\hline Preoperative & $1.4 \pm 14.6$ & $-1.6 \pm 19.1$ & 0.511 \\
\hline IMPO & $-30.6 \pm 9.8$ & $-28.9 \pm 14.3$ & 0.623 \\
\hline Last follow-up & $-30.3 \pm 10$ & $-27.9 \pm 12.7$ & 0.424 \\
\hline Pelvic incidence $\left({ }^{\circ}\right)$ & $54.5 \pm 11.3$ & $58.9 \pm 9.2$ & 0.118 \\
\hline \multicolumn{4}{|l|}{ Pelvic tilt $\left(^{\circ}\right)$} \\
\hline Preoperative & $33.9 \pm 11.4$ & $33.9 \pm 17$ & 0.992 \\
\hline IMPO & $10.8 \pm 7.4$ & $15.1 \pm 10.9$ & 0.102 \\
\hline Last follow-up & $11.1 \pm 7$ & $15.3 \pm 11.2$ & 0.127 \\
\hline \multicolumn{4}{|l|}{ Sacral slope $\left(^{\circ}\right)$} \\
\hline Preoperative & $20.6 \pm 13.5$ & $25 \pm 13.8$ & 0.232 \\
\hline IMPO & $43.7 \pm 10.2$ & $43 \pm 10.3$ & 0.780 \\
\hline Last follow-up & $43.3 \pm 11.1$ & $42.8 \pm 10.5$ & 0.868 \\
\hline \multicolumn{4}{|l|}{ ODI } \\
\hline Preoperative & $37 \pm 2.7$ & $38 \pm 2.3$ & 0.173 \\
\hline IMPO & $19.3 \pm 5.7$ & $22.4 \pm 6.4$ & 0.055 \\
\hline Last follow-up & $9.6 \pm 4.6$ & $13.4 \pm 6.4$ & $0.017^{*}$ \\
\hline \multicolumn{4}{|l|}{ VAS for LBP } \\
\hline Preoperative & $8.1 \pm 1.1$ & $7.7 \pm 1.1$ & 0.132 \\
\hline IMPO & $3.6 \pm 1.9$ & $5 \pm 1.3$ & $0.002^{*}$ \\
\hline Last follow-up & $1.8 \pm 1.3$ & $2.6 \pm 1.4$ & $0.035^{*}$ \\
\hline \multicolumn{4}{|l|}{ VAS for radiating pain } \\
\hline Preoperative & $7.9 \pm 1$ & $8 \pm 0.9$ & 0.556 \\
\hline IMPO & $1.8 \pm 0.9$ & $2 \pm 1$ & 0.512 \\
\hline Last follow-up & $1.3 \pm 1.3$ & $1 \pm 0.8$ & 0.243 \\
\hline
\end{tabular}


TABLE 3. Comparison of predictive risk factors between union and nonunion groups

\begin{tabular}{|c|c|c|c|}
\hline Factor & Union $(n=36)$ & Nonunion $(n=23)$ & $p$ Value \\
\hline Age (yrs) & $70.3 \pm 5.5$ & $68.4 \pm 6.5$ & $0.629^{*}$ \\
\hline $\mathrm{BMI}\left(\mathrm{kg} / \mathrm{m}^{2}\right)$ & $25.7 \pm 3.3$ & $25.5 \pm 3.9$ & $0.322^{*}$ \\
\hline $\mathrm{BMD}\left(\mathrm{g} / \mathrm{cm}^{2}\right)$ & $0.97 \pm 0.26$ & $0.97 \pm 0.22$ & $0.847^{*}$ \\
\hline BMD T-score $\left(\mathrm{g} / \mathrm{cm}^{2}\right)$ & $-1.29 \pm 1.42$ & $-1.31 \pm 1.81$ & $0.799^{*}$ \\
\hline Previous spine surgery (yes/no) & $10 / 26$ & $4 / 19$ & $0.532 \dagger$ \\
\hline PSO (yes/no) & $31 / 5$ & $17 / 6$ & $0.310 \ddagger$ \\
\hline Fused segments & $7.6 \pm 1.2$ & $7.4 \pm 1.3$ & $0.622 \S$ \\
\hline Anterior (ALIF) vs posterior (PLIF) & $27 / 9$ & $17 / 6$ & $1.000 \dagger$ \\
\hline Cage material (metal cage/PEEK cage) & $32 / 4$ & $14 / 9$ & $0.022+\pi$ \\
\hline Sacropelvic fixation (yes/no) & $25 / 11$ & $5 / 18$ & $0.000+\pi$ \\
\hline S2AI vs conventional iliac screw $(n=30)$ & $14 / 11$ & $4 / 1$ & $0.622 \ddagger$ \\
\hline Loosening (yes/no) & $11 / 25$ & $11 / 2$ & $0.270 \dagger$ \\
\hline \multicolumn{4}{|c|}{$\begin{array}{l}\text { Data are presented as the mean } \pm \text { SD or as the number. } \\
\text { * Student t-test. } \\
\text { † Chi-square test. } \\
\text { † Fisher's exact test. } \\
\S \text { Mann-Whitney U-test. } \\
\text { T Statistically significant. }\end{array}$} \\
\hline
\end{tabular}

postoperatively and at the last follow-up than the nonunion group. Although $50 \%$ of patients with pseudarthrosis can be asymptomatic, ${ }^{21}$ the most common symptom is axial or radicular pain..$^{22}$ Since we performed sufficient decompression of the root compression area using a consistent surgical technique in all patients, there was no difference in radiating pain between the two groups. However, the difference in axial pain or low-back pain was likely due to pseudarthrosis caused by L5-S1 nonunion. Moreover, a motor deficit was noted in 3 of the 59 patients in this study: 2 patients in the union group and 1 in the nonunion group. One patient developed neurological complication on the 3rd postoperative day and recovered completely after revision surgery. The 2 other patients had transient nerve root palsy.

\section{Discussion}

Several factors are involved in LS fusion; ${ }^{3}$ therefore, we planned the present study to investigate how these factors come into play during LS fusion surgery. Our results showed that the union and nonunion groups did not significantly differ in terms of patient-related factors, including age, BMI, BMD, and history of spine surgery, as well as in terms of radiological factors, with the exception that the union group showed a higher rate of optimal sagittal balance at the final follow-up. This is attributable to the fact that we included patients with a single etiology known as LDK, and it was a single-center study, allowing the surgical method and criteria to remain consistent. Nevertheless, regarding surgical factors, the two groups significantly differed in terms of sacropelvic fixation and cage material.

LS fixation is crucial as an anchor for long-length constructs during surgical treatment of $\mathrm{ASD}^{7}$ and it is used to improve fusion and postoperative rehabilitation. Nevertheless, poor bone quality and high biomechanical forces at the LS junction among the elderly induce LS pseudarthrosis, thereby causing persistent pain and sagittal imbalance. Despite advances in spinal instrumentation, LS arthrodesis remains a challenging surgical problem for surgeons performing ASD surgery.

\section{Sacropelvic Fixation}

The fact that a combination of long fusion, interbody fusion, and iliac screw fixation increases the stability of the construct and enhances the fusion rate in patients with ASD has been confirmed in numerous studies. ${ }^{3,8,9}$ In an analysis of a large data set including 232 ASD patients, Kim et al. ${ }^{3}$ reported that the nonunion rate decreased to

TABLE 4. Multivariate logistic regression analysis of the influencing factors of postoperative sagittal imbalance

\begin{tabular}{lcccccc}
\hline \multicolumn{1}{c}{ Variable } & $\begin{array}{c}\text { Regression } \\
\text { Coefficient }\end{array}$ & Standard Error & Wald $\chi^{2}$ Value & $p$ Value & Odds Ratio & $95 \% \mathrm{Cl}$ \\
\hline Sacropelvic fixation & -2.218 & 0.697 & 10.117 & $0.001^{*}$ & 0.109 & $0.028-0.427$ \\
\hline PEEK cage & 1.482 & 0.774 & 3.670 & $0.045^{*}$ & 4.402 & $0.966-20.054$ \\
\hline Constant & -0.273 & 0.491 & 0.308 & 0.579 & 0.761 & \\
\hline
\end{tabular}

* Statistically significant $(p<0.05)$ 

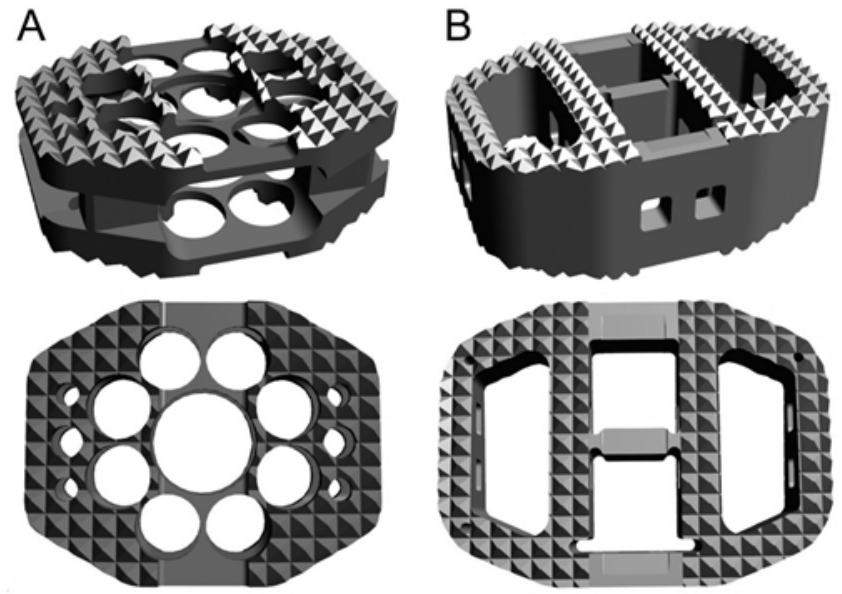

FIG. 2. Schematics for the metal cage (A) and the PEEK cage (B).

below $10 \%$ among patients who underwent the so-called complete sacropelvic fixation involving bilateral S1 screws, bilateral iliac screws, and L5-S1 anterior column support. Lebwohl et al. ${ }^{9}$ also confirmed the effectiveness of reducing screw strain by adding a second fixation point distal to the S1 screws and noted that iliac screw fixation was more effective than any other technique. Furthermore, in an in vitro study using porcine models, both iliac screws and interbody cages effectively reduced the multidirectional flexibility properties of LS junction, and iliac screws particularly suppressed LS junction motion and protected S1 screws. ${ }^{23}$ Similarly, we also found that sacropelvic fixation increased the fusion rate of LS junction. Therefore, using iliac screws with long-segment fusion appears to be essential for improving LS fusion and maintaining sagittal balance in ASD patients.

\section{Metal Cages Versus PEEK Cages}

Interbody fusion using a cage with posterior instrumentation stabilizes the motion segment and improves the fusion rate. It is generally fabricated with metal (titanium) or carbon-fiber composite (PEEK) and is structurally classified as horizontal cylinders, vertical rings, or open boxes. ${ }^{24,25}$ Furthermore, all cages have an opening to achieve successful osseous integration by promoting continuous crossing bony trabeculation between bone graft or bone substitute and adjacent endplates; ${ }^{24}$ they also have small teeth in the superior and inferior surfaces that increase bone-to-implant contact with the adjacent endplates. Nevertheless, the usefulness of titanium and PEEK cages for spinal fusion remains a matter of debate, and there are discrepancies with respect to radiological outcomes and fusion rate settings across studies.

The benefits of titanium include excellent corrosion resistance, low density, and ability to enhance cell adhesion and osseointegration. ${ }^{26,27}$ It has been widely used in bone graft cage or spacers for spinal fusion surgery. Nevertheless, it also has drawbacks, including subsidence of the cage in the adjacent vertebra, difficulties in assessing fusion on radiological imaging, and the stiffness of the material itself. ${ }^{28,29}$ To address these problems, PEEK cages have been introduced. PEEK is a hydrophobic, radiolucent polymer with a biomechanical similarity to cortical bone, and it has been associated with high fusion rates and excellent clinical outcomes in several studies. ${ }^{30,31}$ However, most studies used rhBMP-2; therefore, it is difficult to conclude that the high fusion rate was achieved solely by using PEEK cages. ${ }^{29}$ Moreover, PEEK is chemically inert and does not promote protein absorption, cell adhesion, and bone contact. ${ }^{29,32,33}$ Furthermore, because of manufacturing limitations, PEEK cages do not have surface teeth as sharp as those of the titanium cages and they have a small
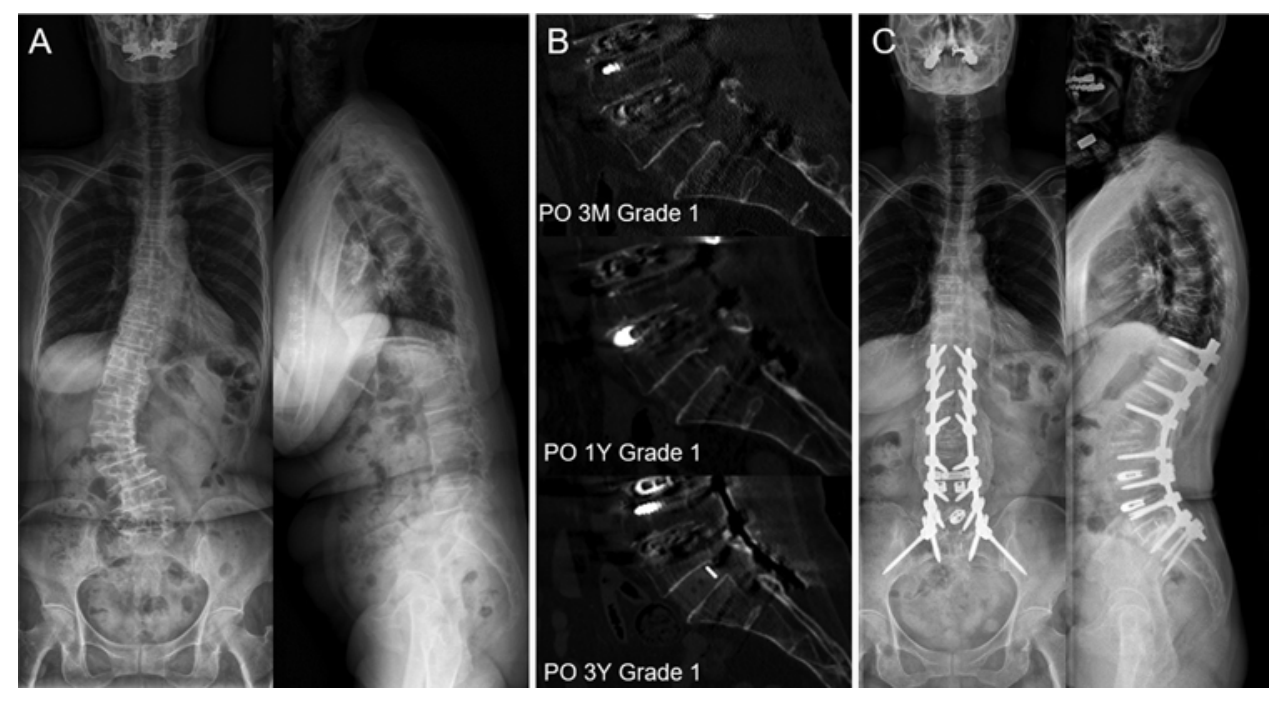

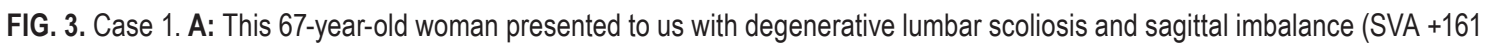
$\mathrm{mm}$, coronal Cobb angle $48^{\circ}$, thoracic kyphosis $[\mathrm{TK}] 2^{\circ}, \mathrm{LL}-17^{\circ}$, PI $55^{\circ}, \mathrm{PT} 20^{\circ}$, and SS $35^{\circ}$ ). We performed a PSO on L2, ALIF on L5-S1 with a PEEK cage, PLIF on L3-4 and L4-5, and posterior instrumented fusion from T10 to S1 with S2Al screw fixation. B: At 3 months, 1 year, and 3 years postoperatively (PO), the patient did not achieve L5-S1 fusion and stability (CT grade 1). C: At 3 years, the patient maintained the coronal and sagittal balance $\left(\mathrm{SVA}+7 \mathrm{~mm}, \mathrm{TK} 37^{\circ}, \mathrm{LL}-80^{\circ}, \mathrm{PT} 4^{\circ}\right.$, and SS $51^{\circ}$ ), but did not achieve L5-S1 fusion and complained of persistent back pain. 


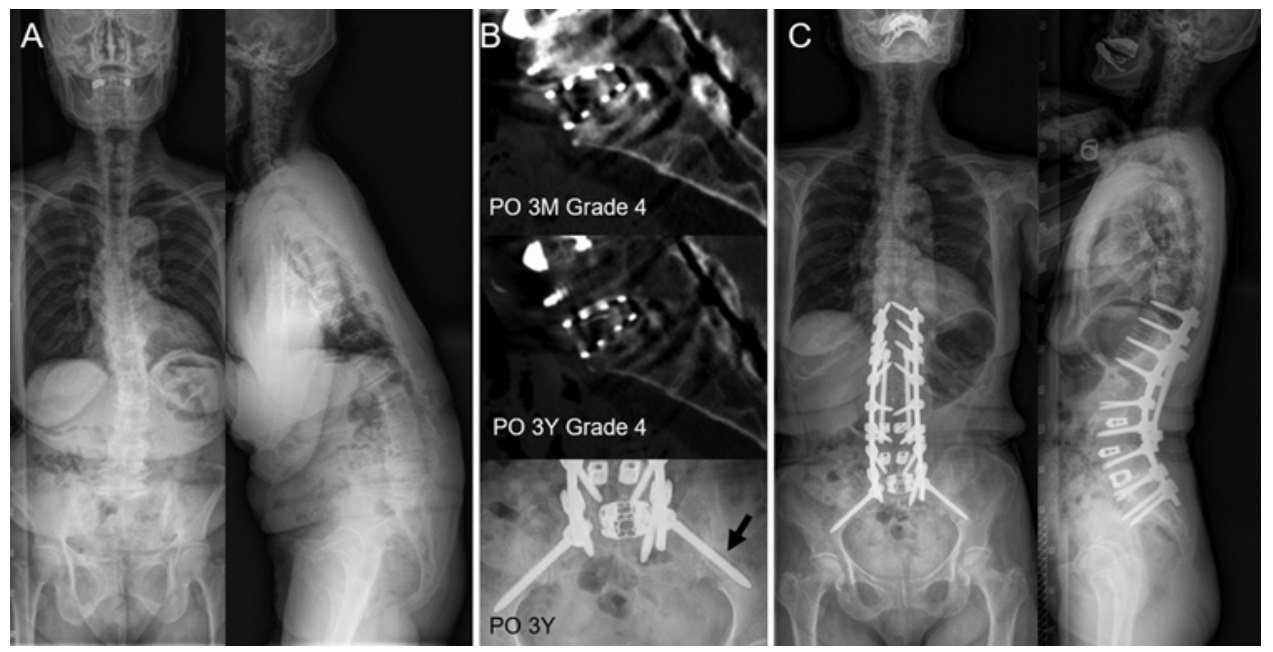

FIG. 4. Case 2. A: This 74 -year-old woman presented to us with degenerative lumbar scoliosis with sagittal imbalance (SVA +189 $\mathrm{mm}$, coronal Cobb angle $16^{\circ}, \mathrm{TK}-10^{\circ}, \mathrm{LL}+35^{\circ}, \mathrm{PI} 45^{\circ}, \mathrm{PT} 42^{\circ}$, and $\mathrm{SS} 3^{\circ}$ ), and we performed a PSO on $\mathrm{L} 2$, ALIF on L5-S1 with a metal cage, PLIF on L3-4 and L4-5, and posterior instrumented fusion from T10 to S1 with S2Al screw fixation. B: At 3 months postoperatively, the patient achieved L5-S1 fusion and stability (CT grade 4), and although the loosening had occurred in the left iliac screw at 3 years postoperatively, L5-S1 fusion was maintained. C: At 3 years postoperatively, the patient maintained coronal and sagittal balance $\left(\mathrm{SVA}+7 \mathrm{~mm}, \mathrm{TK}^{\circ} 7^{\circ}, \mathrm{LL}-80^{\circ}, \mathrm{PT} 4^{\circ}\right.$, and SS $\left.51^{\circ}\right)$, with improved clinical outcomes.

bone-to-implant contact area, possibly causing insufficient anchoring to the endplate (Fig. 2). ${ }^{34,35}$

Nemoto et al. ${ }^{29}$ analyzed CT data from 50 patients who underwent single-level interbody fusion using local bone graft material harvested from the lamina and facet joint and reported that the titanium cage group showed a higher fusion rate than the PEEK cage group. Fujibayashi et al. ${ }^{36}$ also reported that titanium cages had better stability than PEEK cages among patients in whom rhBMP-2 was not used. In our analysis of fusion rates based on 3D-CT scans in patients who underwent L5-S1 interbody fusion, we also found that the fusion rate was higher among patients in whom a titanium cage was used (Figs. 3 and 4). These results showed that, because of structural and chemical properties of the metal, titanium cages are more effective than PEEK cages in achieving LS fusion and stability.

\section{lliac or Sacral Screw Loosening}

Loosening of the fixation mass at the cranial and caudal ends has been frequently observed among patients who undergo multilevel fusion. ${ }^{37}$ However, most patients who have sacral or iliac screw loosening are asymptomatic, and loosening is often accidentally discovered on radiographs obtained during a regular follow-up visit. ${ }^{38}$ Therefore, we analyzed the differences in sacral or iliac screw loosening between L5-S1 union and L5-S1 nonunion patients to investigate the association between sacral or iliac screw loosening and L5-S1 fusion. In our study, 30 of 59 patients underwent spinopelvic fixation. Twentytwo of them showed S1 or iliac screw loosening, while 2 patients showed LS area screw breakage on radiographs and 3D-CT scans. However, we compared patients with L5-S1 union to those with nonunion and found that loosening was not a risk factor for L5-S1 nonunion $(\mathrm{p}=0.270$, Fig. 4).

Cho et $a .^{10}$ conducted a study on LS fixation failure among patients with ASD, based on which they argued that haloing or breakage around the pelvic fixation, which falls under a minor LS fixation failure, is clinically insignificant and that halo formation of the iliac screw is actually a favorable sign, as opposed to a sign of complication. Tokuhashi et al. ${ }^{37}$ also argued that a halo sign around the pelvic fixation does not necessarily indicate pseudarthrosis, and other studies have reported that iliac screw fixation may be vulnerable to loosening over time because the sacroiliac joint is fixed without fusion; however, its clinical importance is unclear, and the halo around the iliac screw may be a sign of stress shielding for S1 screws. ${ }^{39,40}$ In our study, we also found that the L5-S1 union rate was higher among patients who underwent sacropelvic fixation. Moreover, the fact that iliac or sacral screw loosening was insignificant when compared to rates in patients who achieved union suggests that iliac or sacral screw loosening is not a complication and that it does not require revision surgery or iliac screw removal.

\section{Limitations}

There are several limitations to this study. First, as the study was conducted retrospectively, several variables may exist, and the results of the study may have limited implications because the study was conducted at a single institution with all operations performed by a single surgeon. Moreover, this study has the limitation of not using rhBMP-2, which is commonly used nowadays and has shown excellent bone formation in various clinical and in vivo studies. However, the purpose of this study was to focus on the direct factors that influence LS fusion, and this could reduce the errors caused by the change in the fusion rate according to the use of rhBMP-2. Our results confirmed the superiority of the metal cage in LS fusion, and the use of rhBMP-2 with the metal cage may increase the LS fusion rate in deformity surgery for ASD patients. 
As 3D-CT was performed with 3-month intervals postoperatively to analyze the status of LS fusion, the patients were relatively frequently exposed to radiation. However, our results showed that when LS fusion was not achieved after surgical treatment, patients with ASD complained of consistent pain and their global sagittal balance gradually deteriorated, leading to a decline in their quality of life. Hence, we performed CT because we decided that the advantage of accurately examining LS fusion in patients using CT scans obtained at 3-month intervals, which prevents sagittal decompensation or pseudarthrosis, outweighs the risk. ${ }^{41}$ Additionally, various complications and the efficiency of CT were fully explained to the patients and their families, and CT was performed only upon receiving consent. We will attempt to reduce patients' exposure to radiation by performing $\mathrm{CT}$ at longer intervals in the future. Moreover, because CT scans in our study were taken up to 2 years after surgery, there can be concerns about delayed union after 3 years. However, we are monitoring the progress of patients with L5-S1 nonunion through CT at 1-year intervals, and we actually did not observe union in these patients over time in our study. Stauffer and Coventry ${ }^{42}$ showed that pseudarthrosis is mainly observed 6-9 months postoperatively, and Williams et al. ${ }^{43}$ reported that bony arthrodesis is mostly completed by 6 months postoperatively. Hence, we believe that a 2-year follow-up would not be an issue, but we will lengthen the follow-up period in the future so as to report the results on delayed union. Studies of 3D-printed porous titanium cages ${ }^{44}$ with excellent osseointegration, low subsidence, and high fusion rate, which overcome the limitations of the PEEK cage, were not included in this study. However, their efficacy and excellence were not well known when the surgeries were performed in our patients. Moreover, there are inadequate long-term studies on 3D-printed titanium cages to fully confirm their efficacy and safety. ${ }^{45}$ The long-term study, including the use of 3D-printed porous titanium cages, and its results will be reported in the future.

\section{Conclusions}

Our study findings accorded with previous findings, indicating that LS junction fusion is crucial for global sagittal balance and that interbody fusion with iliac screws in addition to long fusion is essential to the surgical treatment of ASD patients. Furthermore, we found that interbody fusion is a useful technique that enhances the stability of the LS junction regardless of the approach (anterior or posterior) and that metal cages were more effective than PEEK cages for promoting LS junction fusion and stability. Therefore, the use of iliac screws, in addition to LS fusion using a metal cage, improves the outcomes of long fusion surgery for ASD patients, and this would serve as a useful guideline for spine surgeons who plan and perform spinal reconstruction surgery.

\section{References}

1. Schwab F, Dubey A, Gamez L, et al. Adult scoliosis: prevalence, SF-36, and nutritional parameters in an elderly volunteer population. Spine (Phila Pa 1976). 2005;30(9):10821085 .
2. Farcy JP, Schwab FJ. Management of flatback and related kyphotic decompensation syndromes. Spine (Phila Pa 1976). 1997;22(20):2452-2457.

3. Kim YJ, Bridwell KH, Lenke LG, et al. Pseudarthrosis in long adult spinal deformity instrumentation and fusion to the sacrum: prevalence and risk factor analysis of 144 cases. Spine (Phila Pa 1976). 2006;31(20):2329-2336.

4. Kostuik JP, Hall BB. Spinal fusions to the sacrum in adults with scoliosis. Spine (Phila Pa 1976). 1983;8(5):489-500.

5. Maeda T, Buchowski JM, Kim YJ, et al. Long adult spinal deformity fusion to the sacrum using rhBMP-2 versus autogenous iliac crest bone graft. Spine (Phila Pa 1976). 2009;34(20):2205-2212.

6. Schwab FJ, Lafage V, Farcy JP, et al. Predicting outcome and complications in the surgical treatment of adult scoliosis. Spine (Phila Pa 1976). 2008;33(20):2243-2247.

7. Kostuik JP, Valdevit A, Chang HG, Kanzaki K. Biomechanical testing of the lumbosacral spine. Spine (Phila Pa 1976). 1998;23(16):1721-1728.

8. Kuklo TR, Bridwell KH, Lewis SJ, et al. Minimum 2-year analysis of sacropelvic fixation and L5-S1 fusion using S1 and iliac screws. Spine (Phila Pa 1976). 2001;26(18):19761983.

9. Lebwohl NH, Cunningham BW, Dmitriev A, et al. Biomechanical comparison of lumbosacral fixation techniques in a calf spine model. Spine (Phila Pa 1976). 2002;27(21):23122320.

10. Cho W, Mason JR, Smith JS, et al. Failure of lumbopelvic fixation after long construct fusions in patients with adult spinal deformity: clinical and radiographic risk factors: clinical article. J Neurosurg Spine. 2013;19(4):445-453.

11. Luhmann SJ, Bridwell KH, Cheng I, et al. Use of bone morphogenetic protein-2 for adult spinal deformity. Spine (Phila Pa 1976). 2005;30(17)(suppl):S110-S117.

12. Mulconrey DS, Bridwell KH, Flynn J, et al. Bone morphogenetic protein (rhBMP-2) as a substitute for iliac crest bone graft in multilevel adult spinal deformity surgery: minimum two-year evaluation of fusion. Spine (Phila Pa 1976). 2008;33(20):2153-2159.

13. Lee CS, Kim YT, Kim E. Clinical study of lumbar degenerative kyphosis. J Korean Soc Spine Surg. 1997;4:27-35.

14. Lee CS, Lee CK, Kim YT, et al. Dynamic sagittal imbalance of the spine in degenerative flat back: significance of pelvic tilt in surgical treatment. Spine (Phila Pa 1976). 2001;26(18):2029-2035.

15. Takemitsu Y, Harada Y, Iwahara T, et al. Lumbar degenerative kyphosis. Clinical, radiological and epidemiological studies. Spine (Phila Pa 1976). 1988;13(11):1317-1326.

16. Horton WC, Brown CW, Bridwell KH, et al. Is there an optimal patient stance for obtaining a lateral 36 " radiograph? A critical comparison of three techniques. Spine (Phila Pa 1976). 2005;30(4):427-433.

17. Lee JH, Kim KT, Lee SH, et al. Overcorrection of lumbar lordosis for adult spinal deformity with sagittal imbalance: comparison of radiographic outcomes between overcorrection and undercorrection. Eur Spine J. 2016;25(8):2668-2675.

18. Smith JS, Bess S, Shaffrey CI, et al. Dynamic changes of the pelvis and spine are key to predicting postoperative sagittal alignment after pedicle subtraction osteotomy: a critical analysis of preoperative planning techniques. Spine (Phila $\mathrm{Pa}$ 1976). 2012;37(10):845-853.

19. Legaye J, Duval-Beaupère G, Hecquet J, Marty C. Pelvic incidence: a fundamental pelvic parameter for three-dimensional regulation of spinal sagittal curves. Eur Spine J. 1998;7(2):99-103.

20. Whang PG, Sasso RC, Patel VV, et al. Comparison of axial and anterior interbody fusions of the L5-S1 segment: a retrospective cohort analysis. J Spinal Disord Tech. 2013;26(8):437-443. 
21. Fischgrund JS, Mackay M, Herkowitz HN, et al. 1997 Volvo Award winner in clinical studies. Degenerative lumbar spondylolisthesis with spinal stenosis: a prospective, randomized study comparing decompressive laminectomy and arthrodesis with and without spinal instrumentation. Spine (Phila Pa 1976). 1997;22(24):2807-2812.

22. Gruskay JA, Webb ML, Grauer JN. Methods of evaluating lumbar and cervical fusion. Spine J. 2014;14(3):531-539.

23. Cunningham BW, Lewis SJ, Long J, et al. Biomechanical evaluation of lumbosacral reconstruction techniques for spondylolisthesis: an in vitro porcine model. Spine (Phila Pa 1976). 2002;27(21):2321-2327.

24. Shah RR, Mohammed S, Saifuddin A, Taylor BA. Comparison of plain radiographs with CT scan to evaluate interbody fusion following the use of titanium interbody cages and transpedicular instrumentation. Eur Spine J. 2003;12(4):378385.

25. Weiner BK, Fraser RD. Spine update lumbar interbody cages. Spine (Phila Pa 1976). 1998;23(5):634-640.

26. Chong E, Pelletier MH, Mobbs RJ, Walsh WR. The design evolution of interbody cages in anterior cervical discectomy and fusion: a systematic review. BMC Musculoskelet Disord. 2015;16:99.

27. Rao PJ, Pelletier MH, Walsh WR, Mobbs RJ. Spine interbody implants: material selection and modification, functionalization and bioactivation of surfaces to improve osseointegration. Orthop Surg. 2014;6(2):81-89.

28. Chen Y, Wang X, Lu X, et al. Comparison of titanium and polyetheretherketone (PEEK) cages in the surgical treatment of multilevel cervical spondylotic myelopathy: a prospective, randomized, control study with over 7-year follow-up. Eur Spine J. 2013;22(7):1539-1546.

29. Nemoto O, Asazuma T, Yato Y, et al. Comparison of fusion rates following transforaminal lumbar interbody fusion using polyetheretherketone cages or titanium cages with transpedicular instrumentation. Eur Spine J. 2014;23(10):2150-2155.

30. Brantigan JW, Steffee AD, Lewis ML, et al. Lumbar interbody fusion using the Brantigan I/F cage for posterior lumbar interbody fusion and the variable pedicle screw placement system: two-year results from a Food and Drug Administration investigational device exemption clinical trial. Spine (Phila Pa 1976). 2000;25(11):1437-1446.

31. Helgeson MD, Lehman RA Jr, Patzkowski JC, et al. Adjacent vertebral body osteolysis with bone morphogenetic protein use in transforaminal lumbar interbody fusion. Spine $J$. 2011;11(6):507-510.

32. De Bartolo L, Morelli S, Bader A, Drioli E. The influence of polymeric membrane surface free energy on cell metabolic functions. J Mater Sci Mater Med. 2001;12(10-12):959-963.

33. Olivares-Navarrete R, Gittens RA, Schneider JM, et al. Osteoblasts exhibit a more differentiated phenotype and increased bone morphogenetic protein production on titanium alloy substrates than on poly-ether-ether-ketone. Spine $J$. 2012;12(3):265-272.

34. Schimmel JJ, Poeschmann MS, Horsting PP, et al. PEEK cages in lumbar fusion: mid-term clinical outcome and radiologic fusion. Clin Spine Surg. 2016;29(5):E252-E258.

35. Spruit M, Falk RG, Beckmann L, et al. The in vitro stabilising effect of polyetheretherketone cages versus a titanium cage of similar design for anterior lumbar interbody fusion. Eur Spine J. 2005;14(8):752-758.
36. Fujibayashi S, Takemoto M, Izeki M, et al. Does the formation of vertebral endplate cysts predict nonunion after lumbar interbody fusion? Spine (Phila Pa 1976). 2012;37(19):E1197E1202.

37. Tokuhashi Y, Matsuzaki H, Oda H, Uei H. Clinical course and significance of the clear zone around the pedicle screws in the lumbar degenerative disease. Spine (Phila Pa 1976). 2008;33(8):903-908.

38. Wu JC, Huang WC, Tsai HW, et al. Pedicle screw loosening in dynamic stabilization: incidence, risk, and outcome in 126 patients. Neurosurg Focus. 2011;31(4):E9.

39. Chang TL, Sponseller PD, Kebaish KM, Fishman EK. Low profile pelvic fixation: anatomic parameters for sacral alariliac fixation versus traditional iliac fixation. Spine (Phila $\mathrm{Pa}$ 1976). 2009;34(5):436-440.

40. Tumialán LM, Mummaneni PV. Long-segment spinal fixation using pelvic screws. Neurosurgery. 2008;63(3)(suppl):183-190.

41. Valentin J. The 2007 Recommendations of the International Commission on Radiological Protection. ICRP publication 103. Ann ICRP. 2007;37(2-4):1-332.

42. Stauffer RN, Coventry MB. Anterior interbody lumbar spine fusion. Analysis of Mayo Clinic series. J Bone Joint Surg Am. 1972;54(4):756-768.

43. Williams AL, Gornet MF, Burkus JK. CT evaluation of lumbar interbody fusion: current concepts. AJNR Am J Neuroradiol. 2005;26(8):2057-2066.

44. McGilvray KC, Easley J, Seim HB, et al. Bony ingrowth potential of 3D-printed porous titanium alloy: a direct comparison of interbody cage materials in an in vivo ovine lumbar fusion model. Spine J. 2018;18(7):1250-1260.

45. Walsh WR, Pelletier MH, Wang T, et al. Does implantation site influence bone ingrowth into 3D-printed porous implants? Spine J. 2019;19(11):1885-1898.

\section{Disclosures}

The authors report no conflict of interest concerning the materials or methods used in this study or the findings specified in this paper.

\section{Author Contributions}

Conception and design: all authors. Acquisition of data: all authors. Analysis and interpretation of data: all authors. Drafting the article: all authors. Critically revising the article: all authors. Reviewed submitted version of manuscript: all authors. Approved the final version of the manuscript on behalf of all authors: $\mathrm{JH}$ Lee. Statistical analysis: all authors. Administrative/technical/ material support: JH Lee, KY Lee, SJ Shin, Im, Park. Study supervision: JH Lee, KY Lee.

\section{Correspondence}

Jung-Hee Lee: Graduate School, College of Medicine, Kyung Hee University, Seoul, Korea. ljhspine@gmail.com. 